\title{
End of Life Care Medical Education: 48 Hour Hospice Home Immersion Alters Students'
} Lives

\author{
J. Kodela1', M. Gugliucci2 ${ }^{*}$, C. Farrell ${ }^{1}$ \\ ${ }^{1}$ University of New England College of Osteopathic Medicine, Biddeford, Maine, USA \\ ${ }^{2}$ Department of Geriatric Medicine, University of New England College of Osteopathic Medicine, Biddeford, \\ Maine, USA \\ Email: "mgugliucci@une.edu
}

Received 21 April 2016; accepted 14 June 2016; published 17 June 2016

Copyright (C) 2016 by authors and Scientific Research Publishing Inc.

This work is licensed under the Creative Commons Attribution International License (CC BY). http://creativecommons.org/licenses/by/4.0/

(c) (7) Open Access

\begin{abstract}
Introduction: Education and skill enhancement in palliative and end of life care is rarely part of the foundational medical education curriculum. The progress of student physicians tends to be measured by their ability to synthesize and demonstrate basic medical knowledge and clinical skills but offers little assessment of the maturation of attitudes or their values. The University of New England College of Osteopathic Medicine (UNECOM), immerses second year medical students in a hospice home for $\mathbf{4 8}$ hours to enhance students' perspectives in interprofessional palliative and end of life care. Methods: This project utilized qualitative ethnographic and autobiographic research designs. Two female second year medical students $(27 \mathrm{y} / \mathrm{o} \& 26 \mathrm{y} / \mathrm{o})$ were immersed for 48 hours into a local hospice home, sleeping in a bed where others had died, to answer the question: "What is it like for ME to live in the Hospice Home for 48 hours and how does this contribute to my future as a practitioner?" Data were collected in the form of journal notes for pre-fieldwork, fieldwork, and post-fieldwork and included subjective and objective reporting of observations, experiences, and patient/family encounters. Analyses included journal review and thematic categorization and coding through content analysis. Results: Themes common to both students that factored in the research question and their prior stated interest areas of medical humanities and person-centered care at end of life were identified. Three themes were selected for this article: 1 ) Person-Centered Experiences, 2) Spectrum of Communication, and 3) Introspection: Attitudes and Values. The process of living in the hospice home for $\mathbf{4 8}$ hours revealed students' attitudes about various disease processes, their personal experiences with death and dying, and their assumptions about how patients approach death. Conclusion: This Hospice Home Immersion project provided both an educational approach and learning environment that was effective in advancing medical students' attitudes, skills, and knowledge as evidenced by their self-reported life altering

"Corresponding author.
\end{abstract}




\section{learning about end of life and palliative care.}

\section{Keywords}

End of Life Care, Palliative Care, Hospice Home, Medical Education, Immersion Learning

\section{Introduction}

The pre-clinical years of medical school (year 1 and year 2) are focused on recognizing and understanding disease; however education and skill enhancement in palliative and end of life care is rarely part of the foundational curriculum. The progress of student physicians during this time is measured by their ability to synthesize and demonstrate basic medical knowledge and clinical skills but offers little assessment of the maturation of attitudes or their values. The attitudes that medical students harness from early childhood through their participation in medical school affect their philosophy about end of life care and the development of good care provision to dying patients and their families [1].

A novel approach to expanding student physician exposure to palliative and end of life care and broadening student perspective through experiential education has been developed at the University of New England College of Osteopathic Medicine (UNECOM). Second year medical students volunteered to pair up for a 48-hour continuous immersion in a hospice home to participate in inter-professional palliative and end of life care. This educational approach and learning environment have been found effective in advancing attitudes, skills, and knowledge for these medical students [2]. The experiences of two students, who conducted this research project, illustrate their pathways for advanced and life-altering learning about end of life and palliative care.

\subsection{End of Life Care in Early Medical Education}

In 1997, the Institute of Medicine published its landmark report: Approaching Death: Improving Care at the End of Life, in which it noted that "the education and training of physicians and other health care professionals fail to provide them the attitudes, knowledge, and skills required to care well for the dying patient” [1] [2]. The medical education community has a responsibility to provide, at the least, competent care for dying patients. Deficiencies in educating future physicians in end of life care reflect a medical culture that defines death as failure and ignores care for dying people as a source of professional accomplishment and personal meaning [1]. Major deficiencies in the end of life medical education include: 1) a curriculum in which death is conspicuous mainly by its relative absence; 2) educational materials that are notable for their inattention to the end stages of most diseases and their neglect of palliative strategies; and 3) clinical experiences for students and residents that largely ignore dying patients and those close to them [1].

Today, nearly all United States medical schools offer some integration of death and dying in the required curricula, but dedicated courses in end of life care exist in fewer than 30\% of schools [3] [4]. Additionally, the dedicated content on this topic is offered through intermittent lectures, case studies/problem-based learning, and possibly brief preceptorships, all of which fail to provide any depth or extended bedside experiences to augment knowledge, skills and attitudes in palliative medicine [5].

Too many first and second year medical students have heard the challenging stories from their peers in third and fourth year clerkships of violent hospital deaths, the discomfort exhibited by attending physicians when they need to address terminal illness with their patients, and the dearth of discussion on advance care planning and options for palliative treatments for patients and their families [6]. Third and fourth year medical students report that they seldom have the opportunity to participate in the care of dying patient and if they do, there is no protected space to reflect or time to formally debrief the situation [7].

Many physicians are remiss in communicating the option of either home hospice (care provided in the person's home) or hospice home care (care provided in an environment dedicated to end of life care) for their patients. An article published in the journal Cancer, reported that when 4074 physicians surveyed were asked about the treatment of a cancer patient with four to six months to live, just 26 percent of the physician respondents indicated they would initiate a conversation about hospice, with 49 percent selecting that they would delay a hospice discussion [8]. 
Such issues are of critical importance to address in medical education and training. The medical school environment has a social responsibility to prepare future physicians especially in the field of end of life and palliative care; no person will avoid death. Medical students, who are unaware of or have unexamined personal anxieties about death, may unconsciously distance themselves from those who are dying. If not explored and understood, this could, in the future, ultimately fail their patients clinically and emotionally [9] [10].

\subsection{Project Inception}

A group of UNECOM students expressed a profound interest in medical humanities and person-centered care; two philosophies that may be best learned in the field. They questioned how they could advance their education to include these practice philosophies that are intimately tied to health and health care with end of life care. These students held the belief that the state-of-mind of a person (who may be a patient) has as profound effect on disease as well as on the body itself. Additionally, they believed that the attitudes and values of a physician shape the person (patient)-physician relationship, which impacts the course of care. These premises framed their 48-hour immersion into the Hospice Home.

\subsection{Hour Hospice Home Immersion Defined}

The Learning by Living 48 Hour Hospice Home Immersion Project (referred to as Hospice Home Immersion) was piloted in December, 2014 [10]. It was designed and implemented as an experiential medical education learning model by the Director of Geriatrics Education and Research within the Medical School's Department of Geriatric Medicine, who is also the project principal investigator (PPI). The Hospice Home Immersion project is based on the long standing and highly successful UNECOM Learning by Living Nursing Home Immersion Project in which medical students and other health professions students are "admitted" into nursing homes to live the life of an older nursing home resident for approximately two weeks—-24 hours a day/7 days a week — complete with medical diagnoses and "standard" procedures of care [11] [12]. However, medical students who participate in the Hospice Home Immersion project are active participants in patient (who die on average within 4.5 days of arriving in the home), family, and post-mortem care during 48 continuous hours rather than assuming the role of "patient or resident" [5]. The purpose of the Hospice Home Immersion project is to provide second through fourth year medical students with firsthand experiences of living in the Hospice of Southern Maine (non-profit) Gosnell Memorial Hospice Home, Scarborough, ME, to answer the question: "What is it like for ME to live in the Hospice Home for 48 hours and how does this contribute to my future as a practitioner?" [5].

\section{Methods}

The Hospice Home Immersion project utilized ethnographic and autobiographic research designs, whereby a unique environment or "culture" (Hospice Home) was observed and the life experiences of the medical student before, during, and immediately after the immersion were reported [5]. As this was conducted with qualitative research methods, students' assumptions were identified rather than hypotheses and there are no variables associated with quantitative research. Written assumptions were based on those thoughts and feelings that each student identified and either accepted as true or believed were certain to happen, without proof. For this article student assumptions were written about what it will be like to live in a hospice home, what to expect from hospice and end of life care, and how each may deal with death. Awareness of these, prior to being immersed, acts as an alert for the students to be aware of and "test" throughout their immersion in the environment.

Two second year medical students were immersed in the Hospice Home for 48 hours at different times. One female student, 27 years old, was immersed in February 2015 and the second female student, 26 years old, was immersed in July 2015. In both immersions, each student selected a fellow classmate to conduct the project with. Students are in good academic standing and volunteer to conduct the project. They completed a registration form that included a written statement about their interest in being immersed for 48 hours and their assumptions. They then met with the project principal investigator (PPI) for an orientation and discussed information about the in-patient hospice home, the research components, the inter-professional staff, and project details for student implementation. Upon being immersed in the Hospice Home, the students participated in a one-hour orientation to the home by the nurse manager [5]. Each student received a name tag and security tag that provided access to all secure areas except the room where drugs were stored. The students were then each paired with a certified 
nursing assistant and then a nurse, eventually working with the physician, chaplain, social worker, volunteers and also on their own throughout the 48 hours. They answered call bells, assisted staff with patient care, engaged with patients and family members, provided post mortem care following a death and participated in inter-professional staff team meetings. At night, they retired to a room set up for patient care and slept in a bed where others have died before [5]. This project was exempt from IRB approval as the student researchers were collecting data focused on self-reflection (autobiographic). The Hospice of Southern Maine Ethics Committee approved the implementation of the UNECOM 48 Hour Hospice Home Immersion project [5].

\section{Data and Analyses}

Data were collected in the form of written journals, in which the students' documented thoughts and feelings during the three stages of ethnographic research: pre-field work (three days prior to entry), field work (during the immersion), and post fieldwork (5 - 7 days after discharge) [5]. Written journals were reviewed and reflected upon at least twice by the students and the Project Principal Investigator (PPI) to identify themes and determine agreed upon definitions for those themes. Then a step by step deductive formulation of content from each journal (representative quotes) were categorized within the appropriate identified themes. Revision of themes and associated content continued throughout the analyses to ensure reliability using formative and summative checks such as reflection on their own experiences with death or their own personality traits. Interpretation of thematic and content analyses culminated in collective final results for the two students [5] [13].

\section{Results}

A combination of their respective results, supported by content that were significant to both students that factored in the research questions and their aforementioned areas of interest of medical humanities and personcentered care are presented. Three themes meeting these criteria were selected: 1) Person-Centered Experiences, 2) Spectrum of Communication, and 3) Introspection: Attitudes and Values. Presented below, in their voices, were the experiences and resultant reflections that instilled learning.

\subsection{Theme 1. Person-Centered Experiences}

"There was one patient that I had who was a younger woman. She was grasping at the air and trying to push it away. In the hospital, that would be seen as a delusion and would have been heavily medicated. But I asked her, what do you see? She saw all of these people who she knew, but she was trying to push them aside. She wanted her dad. She was trying to get to her dad. That was what she was seeing in her dying process... Terry (pseudonym), the hospice nurse, told me that what patients see when they are dying may not be real to us, but it is real to them. It is their reality". (C. Farrell, OMS III, 2015)

"Nancy (pseudonym) said on several occasions prior to her death that 'she wasn't ready to go'. She was concerned because her husband would no longer be receiving her social security check and could not afford basic living expenses, she had 'so many people she loved that she wasn't able to say goodbye to', and she didn't know who would take care of her family. The day Nancy died she had a terrible pain crisis that took some time to control. The staff told me that this often happened when someone was going through existential pain. When she died, though, she was relieved of the physical pain, but the existential pain was still present”. (J. Kodela, OMS III, 2015)

Our first instincts were to think about the physical symptoms of our respective patients; to establish a differential diagnosis for delusions or for pain. It took further reflection to realize that the key was not to label this behavior as abnormal and identify an etiology, but instead to acknowledge the behavior as an expression of the person's state-of-mind. It was evident from living in the Hospice Home for 48 hours that there were aspects of pain and suffering that escaped the traditional understanding of physiology that we learned during two years of medical school. On a number of occasions, we encountered various patients with uncontrollable pain, despite traditional management and high doses of analgesics. Over time and with information shared by the hospice staff we began to understand that not all symptoms are physiologically based. There are psychological manifestations that may go beyond medical understanding. The term that was used at the hospice home was "dysfunctional dying”.

"It (dysfunctional dying) is usually in patients who had a tough life, she (hospice nurse) explained, such as 
substance use or sexual or physical abuse. These patients have so much pain from their life that they cannot die peacefully. They feel agitated, get out of bed, are looking for something but don't know what. This is real pain. That existential pain that is manifested as physical pain. It is their spiritual dysfunction manifested as physical disturbance”. (C. Farrell, OMS III, 2015)

This concept was something new and foreign and certainly not taught in our medical school. Experiencing and observing different forms of dying helped in understanding the holistic nature of disease, specifically the influence of the mind and spirit on the body. Although this is a concept that osteopathic medicine embraces, as students, we were not able to explore it in relation to palliative care and the dying process through our curriculum. It was made evident during our time in the Hospice Home how the contribution of person-centered stateof-mind affects overall health, and appears to be magnified during end of life care.

\subsection{Theme 2. Spectrum of Communication}

"Greta (pseudonym) is clearly awake and responsive, but has lost her speech. She looks straight at you when you talk to her. She sits up in bed clutching her cross. I wonder if she knows where she is and what has happened to her. I wonder if she is scared. I wonder if she is happy that I am there". (C. Farrell, OMS III, 2015)

"I realized that I am someone who typically relies on conversation. I'm uncomfortable with silence. In the more intimate experiences I had with families, I couldn't rely on conversation or even find meaningful words. This left me with silence. Though I didn't initially pick up on that as part of the source of my discomfort, I realized that I became much more relaxed when I acknowledged eye contact and body language as a source of communication". (J. Kodela, OMS III, 2015)

Communication goes far beyond words. We questioned when writing our pre field-notes, prior to entering the Hospice Home, whether we would know what words to say to patients or their family. Feelings of "uneasiness" and being "unequipped" were deeply felt and we both wrote about this in our journals. Pre-clinical medical education did not prepare us for these difficult conversations nor did we feel that role playing or reading about how to communicate with a dying person and their family would have prepared us for the myriad of issues that arose during the dying process or at the time of death while in the home. We learned quickly that dying is complicated and complex for some, not everyone goes peacefully. Though we felt well prepared to express ourselves, in that we believe ourselves to be articulate communicators, the value of spoken words was depreciated within the hospice setting. We realized that communication can be insignificant or imprudent when one only relies on spoken words. Upon reflecting on our experiences we realized how much we read body language and listened to what was expressed beyond words.

"I kept thinking about how language can fail us. The conversation with Rachel (pseudonym), the hospice chaplain really stuck with me. I thought about how terribly misplaced the words would have been had I told a family like Nancy's 'she's at peace'. It's a silly assumption to think that everyone who has passed is completely at peace”. (J. Kodela, OMS III, 2015)

In this situation, the patient had been tormented by unresolved life experiences. Though she had passed, these concerns lingered or were not laid to rest. Colloquialisms like "at peace" and "in a better place" are often offered to the family, but their use can be unfitting without familiarity of the dying person and his/her family. In turn, we realized that communication through a quiet presence or nonverbal exchange was invaluable and respected and honored the person and the family. We arrived at the conclusion that effective communication is much more than words, and is a pillar of quality health care.

"Communication should be the number one priority of all healthcare settings. I think we learn this to a certain extent in medical school and we attempt to improve our communication among inter-professional teams. I think hospice does a great job with this. But I hadn't thought as much about the barriers to communication with patients, especially those who have lost their ability to speak". (C. Farrell, OMSIII, 2015)

Effective and meaningful communication at the end of life or through the palliative process relies on internal congruence, meaning that the three aforementioned elements (words, voice tone, and body language) support each other. The Hospice Home Immersion raised our communication consciousness and emphasized the importance of cultivating the tools necessary to mindfully communicate through action, tone, and words.

\subsection{Theme 3. Introspection: Attitudes and Values}

The Hospice Home Immersion was emotional. We each carried our own familiarity with death and dying, which 
impacted the way in which we each responded to varying events in the hospice environment.

"I am afraid that I will be too emotional, because I know that lying just beneath the surface are my own painful memories. I do not want to inflict my pain and suffering on someone else, most of all someone that I am trying to help and learn from. But I also want to maintain my humanity... I am still learning how to walk the line of being compassionate and professional". (C. Farrell, OMS III, 2015)

Self-assessment and reflection were prominent themes throughout our journaling process and aided in advancing our learning about medical humanities and person-centered care. At times during the immersion, this reflection revealed unexpected biases. I was part of a discussion about a person dying from alcoholic cirrhosis. This patient had left home at an early age and only reached out to family in times of crisis. At the close of this encounter I thought long and hard about what I was thinking and feeling, finally I wrote:

"His story didn't impact me immediately, until Rachel (pseudonym), the hospice chaplain, said 'Isn't his story inspiring? I wouldn't be able to survive homeless for 22 years. Just a really powerful story'. I realized in that moment that I was already becoming the (student) physician that I loathed. As I heard the details of his case, I had immediately felt badly for the family and judged Don (pseudonym). I had thought that it must have been terrible for the family to watch Don make so many bad decisions and wondered why he had so much trouble. Though I hadn't voiced any of this, I was instantly embarrassed by my thoughts. The discussion with Rachel was incredibly valuable and grounding”. (J. Kodela, OMS III)

There were times that our assumptions about patient desires during end of life care were misguided.

"Sometimes as providers you make assumptions about what the patient wants. I stayed up with Diana (pseudonym) all night, thinking that I did not want her to die alone. This morning I learned that she had died about an hour after I went to bed. I felt pretty upset about this and thought I should have stayed with her. But then I was reminded that maybe that was not what Diana wanted. Maybe she wanted to be alone. So I think being in tune with my patients by putting my own desires and perceptions aside, will help me be more open to them". (C. Farrell, OMS III, 2015)

This level of person-centered care and awareness relies on far more that than medical knowledge, it was amazing to us how much we learned through experience in 48 hours. The Hospice Home Immersion project obliged us to move out of our comfort zone; we each spent 48 continuous hours engaging with upwards of 14 dying patients and their families, we got little sleep, and when either of us did sleep we were in a bed where others have died before. This combination of experiences along with staff guidance accelerated our introspection and created comprehensive learning about end of life care. We gained competence throughout the 48 hour immersion as well as confidence.

\section{Discussion}

The topics of death and dying, palliative and end of life care are generally lacking in modern medical education. Most medical students will have little to no experience with these topics until they are faced with patients during their clinical rotations, for which they may receive varying levels of guidance from their superiors [7].

The Hospice Home Immersion project proved to be an effective learning tool for these students during their pre-clinical years. By living at the Gosnell Memorial Hospice Home for 48 hours, the students were able to develop skills on site and immediately utilize these with patients and families facing death. As evidenced through their ethnographic journaling, the students identified three themes that underscored their immersion: person-centered experiences, spectrum of communication, and introspection.

Through this project, the students were exposed to aspects of death and dying that were not easily explained pathologically. The students observed that not all symptoms experienced by the patients were physiologically based. This lead them to an understanding that medical care is multifactorial, and includes the physical, emotional, and spiritual aspect of a person. While this philosophy may be mentioned in traditional medical education practices, the emphasis has always remained in the physical dimension. By living in the hospice home, the students came to understand and appreciate the other aspects of a patient's life and how those aspects play a role in the dying process.

Communication is vital to healthcare. Reflected in their journals was the original belief that communication lies strictly in the verbal sphere. Often emphasized in medical education is the proper terminology and language to be used when communicating with patients, as well as with other providers. However, the non-verbal forms of communication that are often overlooked are essential when providing patient and family care. According to Mehrabian [14], the power of body language and voice tone in aiding communication is often not recognized 
and yet it accounts for $93 \%$ of communication (voice tone accounts for $38 \%$, and body language accounts for $55 \%$ ), with words accounting for only $7 \%$ of communications [14]. Both students remarked that they felt trepidation about finding the correct words to use in the presence of dying patients. Once in the home they learned that other forms of communication are as meaningful and powerful, such as touch, silence, and mere presence. Care was effective without long conversations. Furthermore, the students developed the skills and aptitude to understand when a conversation may be warranted, and when other forms of communication would be best utilized.

Lastly, the Hospice Home Immersion project allowed the students to gain insight into their own attitudes and biases about death and dying. The process of living in a hospice home revealed students' attitudes about various disease processes, their personal experiences with death and dying, and their assumptions about how patients approach death. The project revealed the students' own biases on numerous occasions. Both students remarked on how their perceptions were misguided, be it in the form of how a patient wanted to die, or their perception of a family situation and disease. Overall, the Hospice Home Immersion project compelled the students to explore and challenge their assumptions surrounding the dying process. At the conclusion of their immersion, both students expressed gratitude for the experience, a greater depth of understanding of palliative and end of life care, and a newfound self-awareness.

\section{Limitations}

This article presents the experiences and outcomes of two of the twenty-six students who have conducted this project and research thus far. The results are specific to these two students and therefore may not be applied to all medical students. However, through this immersion project, each pair of students learning about palliative, end of life, and inter-professional care is being advanced; even if only by two students at a time. The Hospice Home Immersion project aggregate data analysis is in progress, however, as true with qualitative outcomes the results stated by each person who conducts this research is significant for that person.

\section{Conclusions}

Early medical education succeeds in equipping students with a foundation in the pathophysiology of disease and the performance of foundational clinical skills. There is considerably less emphasis placed on palliative and end of life care. Although, as previously stated, it has been well documented that the attitudes and values of a physician impact the care of their patients, assessment of the maturation of the student physician is lacking.

The 48 Hour Hospice Home Immersion project addresses this deficit by providing in-depth and experiential learning that encourages self-reflection. These pioneer students expressed a desire to mature as student physicians, to learn about person-centered care, and to operationalize medical humanities within a health care environment. The Gosnell Memorial Hospice Home and its inter-professional team of staff and volunteers taught these UNECOM medical students far more than mere medical care at the end of life. Instead, these students learned skills that will serve them throughout their careers, such as awareness of the person/patient, communication, and reflection/introspection. There is no question that medical education can do a better job in educating our future physicians in the field of palliative medicine. Maybe someday we can count on our medical schools to teach basic level competence in the care of the dying person, but will this instill confidence? As physicians they will be expected to perform palliative and humanistic skills, hopefully beyond the basic level [2].

The recommendations based on the outcomes of this project thus far, are to immerse our pre-clinical and clinical medical students into an in-patient hospice environment and have them work side by side with inter-professional staff and directly with patients and families during the palliative and end of life care phases. If experience is the best teacher then an essential first step, to learn what exemplary care entails for dying persons and their family, may be an extended immersion within an exceptional end of life care environment.

\section{References}

[1] Field, M.J. and Cassel, C.K., Eds. (1997) Committee on Care at the End of Life. Approaching Death: Improving Care at the End of Life. Institute of Medicine-National Academy Press, Washington DC.

[2] IOM (Institute of Medicine) (2015) Dying in America: Improving Quality and Honoring Individual Preferences near the End of Life. The National Academies Press, Washington DC.

[3] Dickinson, G.E. (2006) Teaching End-of-Life Issues in US Medical Schools: 1975 to 2005. American Journal of Hos- 
pice \& Palliative Medicine, 23, 197-204. http://dx.doi.org/10.1177/1049909106289066

[4] Sullivan, A.M., Warren, A.G., Lakoma, M.D., Liaw, K.R., Hwang, D. and Block, S.D. (2004) End-of-Life Care in the Curriculum: A National Study of Medical Education Deans. Academic Medicine, 79, 760-768. http://dx.doi.org/10.1097/00001888-200408000-00011

[5] Gugliucci, M., Malhotra, H. and Gaul, A. (2015) Hospice Home Immersion Project: Advancing Medical Education. International Journal of Clinical Medicine, 6, 158-169. http://dx.doi.org/10.4236/ijcm.2015.63021

[6] ABIM-American Board of Internal Medicine (1996) Caring for the Dying: Identification and Promotion of Physician Competency: Personal Narratives. American Board of Internal Medicine, Philadelphia.

[7] Head, B.A., Schapmire, T.J., Earnshaw, L., Chenault, J., Pfeifer, M., Sawning, S. and Shaw, M.A. (2016) Improving Medical Graduates’ Training in Palliative Care: Advancing Education and Practice. Advances in Medical Education and Practice, 7, 99-113. http://dx.doi.org/10.2147/AMEP.S94550

[8] Keating, N.L., Landrum, M.B., Lamont, E.B., Earle, C.C., Bozeman, S.R. and McNeil, B.J. (2010) End-of-Life Care for Older Cancer Patients in the Veterans Health Administration versus the Private Sector. Cancer, 116, 3732-3739. http://dx.doi.org/10.1002/cncr.25077

[9] Vargo, M.E. and Black, W. (1984) Attribution of Control and the Fear of Death among First-Year Medical Students. Journal of Clinical Psychology, 40, 1525-1528.

[10] Williams, C.M., Wilson, C.C. and Olsen, C.H. (2005) Dying, Death, and Medical Education: Student Voices. Journal of Palliative Medicine, 8, 376. http://dx.doi.org/10.1089/jpm.2005.8.372

[11] Gugliucci, M. and Weiner, A. (2013) Learning by Living: Life-Altering Medical Education through Nursing HomeBased Experiential Learning. Gerontology \& Geriatrics Education, 34, 60-77. http://dx.doi.org/10.1080/02701960.2013.749254

[12] Hondros-McCarthy, I., Barber, P. and Gugliucci, M.R. (2016) Learning by Living: Empathy Learned through an Extended Medical Education Immersion Project. International Journal of Clinical Medicine, 7, 236-244. http://dx.doi.org/10.4236/ijcm.2016.73025

[13] Mayring, P. (2000) Qualitative Content Analysis [28 Paragraphs]. Forum: Qualitative Social Research, 1, Art. 20. http://nbn-resolving.de/urn:nbn:de:0114-fqs0002204

[14] Mehrabian, A. (1971) Silent Messages. Wadsworth, Belmont. 